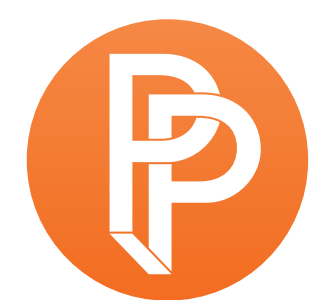

PERFORMANCE

PHILOSOPHY

\title{
EMBODIMENT AS FIRST AFFORDANCE: TINKERING, TUNING, TRACKING
}

\author{
BEN SPATZ UNIVERSITY OF HUDDERSFIELD
}

\section{What is embodiment?}

In a diverse range of recent research activities, I have worked to develop productive distinctions between embodied knowledge, embodied practice, embodied technique, and embodied research; but I have settled for a brief gloss of the crucial descriptor 'embodied' (Spatz 2015, 1114). ${ }^{1}$ In this essay I offer a critical and philosophical approach to embodiment, explaining why we continue to need this concept and what I believe it can still do for us.

Thomas Csordas wrote more than twenty-five years ago that embodiment can be 'a paradigm for anthropology': that is, a 'consistent methodological perspective that encourages reanalyses of existing data and suggests new questions for empirical research' $(1990,5)$. Summarizing Marcel Mauss, Csordas indicates the centrality of embodiment as a zone of mediation or junction between various dichotomies and material distinctions:

\footnotetext{
Mauss anticipated how a paradigm of embodiment might mediate fundamental dualities (mind-body, sign-significance, existence-being) in his statement that the body is simultaneously both the original object upon which the work of culture is carried out, and the original tool with which that work is achieved. It is at once an object of technique, a technical means, and the subjective origin of technique. (Csordas 1990, 11)
} 
Arguably, we are still some distance from the implementation of embodiment as a paradigm within performance studies, performance philosophy, and artistic research. I suspect this is because our understanding of embodiment-which like that of Csordas is most often based on Merleau-Ponty's phenomenology_fails to adequately develop themes of difference, materiality, epistemology, and practice, tending instead towards a more general or unitary understanding of embodiment. In this essay, I look again at embodiment with an eye towards these themes and attempt to develop further the kind of paradigm toward which Csordas gestures. My aim is to create spaces of possibility for experimental approaches to anthropology and performance (as) philosophy.

My argument begins from a discussion of philosophical realism and the turn towards close analysis of skilled material practices that characterizes many recent critical interventions. I examine the roots of this turn and suggest that skilled practice is a privileged site for the enactment and testing of realist ontologies. However, I question the extent to which realist thinkers have emphasized practices in which materials outside the body are central over those in which embodiment itself is the primary medium of practice. ${ }^{2}$ Thinkers of realist ontology, I argue, have neglected embodiment as the primary site of engagement with the fine-grained detail of the world. In fact, realist ontologies developed through reference to technological and 'machinic' worldly engagements not only apply equally well to embodied practices, but actually find their original and primary manifestation there. The body itself is the first affordance and the site at which questions of realism and objectivity are first encountered and resolved in practice. I illustrate this point by considering how three modes of material engagement-tinkering, tuning, and tracking-manifest in embodied practices ranging from dance and sport to those of everyday life. From quotidian enculturation to virtuosic performance, skilful embodied practice is neither more nor less than a precise and intimate engagement with the problematic of realism in its most fundamental form. I therefore propose a return to embodiment for realist thought: one that passes through the phenomenological modes of perception and sensation to the epistemic mode of technique. ${ }^{3}$ I conclude by articulating the continuing political importance of embodiment as first affordance and its crucial place as a 'fragile junction' between ecology and technology.

\section{Artisanal Ontologies}

Two types of encounter with the emergent granularity of the material world have been seen in recent critical and philosophical writing as privileged sites for the investigation of ontological realism: artisan craft and scientific experiment. ${ }^{4}$ Examples of the former include Tim Ingold's poetic descriptions of the 'synergy of practitioner, tool and material' $(2011,56)$ and Richard Sennett's paean to craftwork as a 'dialogue with materials' $(2009,268)$. The latter are found throughout sociological studies of science such as those undertaken by Andrew Pickering (1995) and Karin Knorr Cetina (1999). Both artisanal crafts and scientific experimentation involve a subtle and complex interplay between skilled handicraft and the emergent properties of materials. While craftwork aims to produce well-made objects of a known type or style, the objects produced and encountered by scientific research are by definition unknown at the start of the experimental 
process. What unites the two domains is the dynamic process of material engagement through which the fine-grained texture of reality emerges. This kind of continuous grappling or negotiation with ever-unfolding layers of detail is equally far from pure mentality or cognition as it is from the play of immaterial signs. In skilled practice, one knows that something is real in the sense of being out there (not just imaginary) through the sensation of differential 'resistance' (Pickering 1995) or push-back and also because, rather than shrinking as it becomes known, the area of focus rapidly expands as deeper engagement reveals ever-greater levels of detail (Cetina in Schatzki et al. 2001).

According to such analyses, the world 'talks back' to us (Sennett 2009, 272) most articulately not when we step away from it to contemplate its totality but when we dive into it to accomplish a specific material task: to pick up a batch of seeds we have dropped on the floor; to construct a tool out of wood or metal; to harness the power of a protein or a proton. The stubborn independence of the individual bits and pieces in such material interactions compels us to recognize a reality that exists beyond our own sensations, perceptions, and thoughts. This kind of realism has no truck with the long-standing mind/body 'problem' that still seems to bother philosophers of cognition (Lakoff and Johnson 1999). That apparent problem only arises if one starts with a disembodied, language-based mind and then asks how to bridge the gap between this mind and reality. ${ }^{5}$ If one begins instead from practices as concrete doings (Schatzki et al. 2001), that disembodied mind never appears. The care with which an artisan craftworker or scientist grapples with their chosen material substrate thus incarnates a particular approach to ontology. Instead of asking whether reality exists, the artisan takes the principle of existence for granted and works with the productive problems and questions that arise from its complexity, stubbornness, and only-ever relative reliability. Theorists of skilled practice articulate realism in terms of dynamic relations rather than static beings: as a 'coupling of perception and action' (Ingold 2011, 58); a 'dialectic between resistance and accommodation' (Pickering 1995, 22); or an 'intimate, fluid join between problem solving and problem finding' (Sennett 2009, 33). Such approaches are quite different from those armchair philosophies that attempt to theorize the real in general, often by rendering invisible their debt to the emergent and relational ontologies of practice.

Despite these advantages, the cited works share a common assumption that is rarely questioned. All of the dynamic interplays just mentioned are incarnated in practices that rely upon a clear physical distinction between human agent and nonhuman material substrate. By taking scientists, inventors, and artisan craftworkers as their examples, these thinkers continually reinscribe a basic division between practitioner and materials. A significant territory of ontological experimentation is in this way bypassed: that of embodiment itself as the primary site of any encounter with reality. To be sure, the actual material practices investigated by the cited authors vary greatly, from biochemists and particle physicists to carpenters, glass-blowers, and goldsmiths. But all of these cases present a clear image of human beings working with materials outside their bodies. Time and again, the careful action of the artisan or scientist is figured in relation to an external material: wood, metal, stone, glass, water, protein, quark, etc. Laurent Thévenot even goes so far as to define realism as 'the relation between human agency and material environment' (in Schatzki et al. 2001, 58). I read this as a welcome ontological reframing of James Gibson's notion of 'affordances', those possibilities that a given physical environment 'offers', 'provides', or 'furnishes' to an 'animal' that 
lives within it $(1979,127)$. But this ontological step is incomplete if it remains locked within a dualist image that juxtaposes an agent or animal with its environment. Rarely has the kind of analysis outlined above been applied to the first and most essential material factor in human being: embodiment itself. Yet before wood, glass, metal, or any other external material substrate, embodiment itself is the first affordance.

The negotiated relationship between organism and environment is an extension of a relationship that develops internally within an organism and which may later be articulated in terms of mind and body, will and habit, or knowledge and practice. Why then have recent turns toward philosophical realism not engaged more thoroughly with embodiment as first affordance? Why do thinkers like Thévenot render the body invisible with phrases like 'human agency and material environment', which skip over the essential channel of human materiality through which agency and environment interact? I suspect that the invisibility of the body in passages like this one reveals an unconscious prejudice against-or perhaps more simply a lack of understanding about-the nature of skilled embodied practices. This lack is apparent even in philosophical approaches that seek to foreground embodiment, such as phenomenology. While the thinkers cited above emphasize the complexity and specificity of material processes, phenomenology has tended to treat the body as functionally uniform in its materiality. Even when thinkers attempt to ground mind and cognition in materiality by calling them 'embodied', their account of embodiment as a largely 'postural and static' phenomenon is 'emaciated' in comparison with the actual complexity of any 'animate organism' (Sheets-Johnstone 2015, 28). Sara Ahmed has done important work to challenge the assumed uniformity of the embodied mind by pointing to ways in which the 'repetition of norms and conventions, of routes and paths taken', gradually leads to the development of 'a specific "take" on the world, a set of views and viewing points, as well as a route through the contours of the world, which gives our world its own contours' (2006, 16-17). Ahmed's evocation of these historical processes of differential sedimentation (41) and how they congeal in bodily comportment (56) suggests the need to examine embodiment as a complex, multidimensional space. 'It is important that we think not only about what is repeated,' she writes, 'but also about how the repetition of actions takes us in certain directions'. But Ahmed only gestures towards the possibility of a fine-grained queer and critical-race oriented analysis of embodiment; she does not provide a detailed reading of concrete practices to rival those mentioned above. ${ }^{6}$

In the wake of phenomenology's 'anthropocentric antirealism' (Sparrow 2014), philosophers still tend to think of the body as more unitary or transparent than the kinds of external materials with which artisans and scientists grapple. While lip service may be paid to the diversity of bodily experience along various lines, there is nothing comparable to the appreciation of fractal disciplinarity that one finds in the sociology of science or the anthropology of skilled practice, where depth of practice is valorized because of how it reveals the emergent complexity of the real. The body, philosophers seem to think, is a poor starting place from which to grasp the emergent diversity and multivocality of the material world. Although some diversity in embodiment may be recognized, the body affords nothing comparable to the vast territories of biology and physics, or the many artisan crafts, that attract philosophers of skilled practice. The apparent commonality of 
embodiment, when contrasted with the kaleidoscopic variety afforded by the subatomic bestiary or the liquid flows of craftwork, tempts thinkers of realism to skip over the body as an essential site for understanding the real. But this gets embodiment wrong. In fact, our relationships with our bodies-more accurately, with ourselves as bodies-is characterized by exactly the same kind of fine-grained engagement and dynamic interplay with materiality as artisanal and technoscientific practices. Just as every chunk of wood or metal has both relative reliability as an example of that substrate and also a unique individual structure of resistance and density with which the artisan or scientist must work, so too does each human body. There is a kaleidoscopic unfolding of embodiment; it merely remains to be theorized. ${ }^{7}$

I take embodiment to be the zone of ontological engagement in which the dynamic interplays mentioned above-between perception and action, resistance and accommodation, and problemsolving and problem-finding-occur in the absence of any clear physical distinction between agent and substrate. Examples like carpentry illustrate these interplays with great clarity, but in doing so they risk a problematic reification in which the two sides of each equation are easily distinguished: on one side, a human agent; on the other, a material substrate. In fact, both sides of each equation also exist in fluid and indiscernible mixture within human embodiment itself. We see this clearly in ritual and theatrical performances, a topic studied in depth by anthropology and performance studies but which rarely commands the attention of philosophers. Philosophers tend to think of embodied performance as merely cultural, a representational layer of activity enacted by an essentially uniform substrate of bodies, and therefore irrelevant to ontological questions about the real. If that were true, then it could make sense to jump directly from consciousness, perception, and experience, on the one hand, to external worlds of materiality, objects, and ecologies, on the other. On the contrary, embodiment itself is as much a hard-won negotiation with material possibility-and therefore a privileged site for the concrete manifestation of realist ontologies-as any engagement with wood, glass or proteins. Moreover, as Ahmed shows, the diversity and complexity of embodiment applies not only to practices framed as ritual or performance but also to those of everyday life. I will go further and claim that the affordance of embodiment is logically prior to that of any external physical environment, not because embodiment is synonymous with perception-it is not-but because it is the first site at which the dialogue between agency and materiality takes place. In the next section I unpack this claim through a series of illustrative examples. In the final section I argue that the concept of embodiment as first affordance still has important ethical and political work to do.

\section{Tinkering, Tuning, Tracking}

To demonstrate the extent to which both everyday and virtuosic embodied practices incarnate the ontological realism implied by skilled practice, I will borrow three terms from three major theorists of artisanal ontology. As early as 1979, Karin Knorr Cetina described scientific laboratory work as a kind of 'tinkering'. Science is not primarily about ideas, she explained, but about practices. Its goal is not the production of propositional truths or facts but successful interaction with material reality. 
Hence 'the mechanisms ruling the progress of research are more adequately described as successful "tinkering" rather than as hypothesis testing or cumulative verification' (Knorr 1979, 350). Some years later, Andrew Pickering proposed a shift from 'tinkering' to 'tuning'. Whereas the former 'immediately invokes the otherness' of the materials encountered by the scientist, the latter suggests a kind of mutual resonance between them (1995, 14n22). For Pickering, the scientist does not so much tinker with materials as tune them, or perhaps attune to them-more like a musician than a mechanic. Between these two publications, Manuel De Landa wrote his extraordinary history of war from the perspective of its varied technologies, which he described as arising from the expert 'tracking' of material singularities $(1991,26)$. To track the melting or combustion point required in the production of a particular weapon, De Landa writes, involves a 'sensual interplay with metals' in which the artisan/inventor works with care to 'follow the accidents and local vagaries of a given piece of material' (30). In each of the cases studied by these authors, the sensitive relationship between practitioner and material suggests a revised notion of realism in which the reality of the world becomes manifest through the painstaking labour of craft and experimentation. The terms tinkering, tuning, and tracking suggest three different qualities of engagement with materiality. ${ }^{8}$ In this section I apply them each in turn to practices that are specifically embodied-in the sense defined above-rather than technological; that is, situations in which tinkering, tuning, and tracking take place not between a human agent and a material substrate but within human embodiment itself.

Tinkering suggests a process of combining and recombining bits and pieces almost at random in order to see what works. The smaller elements in a tinkering practice are individually functional; the pertinent question is in what way they can best be combined. We encounter this kind of approach often when structuring embodied practice in time and space, as in both pedagogy and choreography. How should participants be arranged in space-in a line or in a circle? What should be the sequence of events? What happens if this activity comes after that one? What if an activity drawn from another context is inserted here? How do the different elements interact? What occurs when two elements are switched around in space or in time? What if one section is removed? As we tinker, we encounter expected results. Oh, that's interesting. Now let's try something else... A structure of practice is articulated and enacted, adjustments are made, the whole thing is repeated, one part is dismantled, the order is reversed, chunks are taken apart and reassembled in a different way. The teacher, choreographer, theatre director, or ritual leader tinkers with the structure of repeated doings. The outcomes of such tinkering acts are rarely measurable in quantitative terms. Because the smaller elements are taken for granted rather than being broken down or opened up, tinkering is primarily a matter of composition. For this reason too, it is often not clear when tinkering whether the situation is getting better or worse. And even when there is clear improvement, one may wonder if the situation could be made better still. Tinkering may continue indefinitely.

Acts of tinkering are no less prevalent in everyday life than in professional and vocational contexts. Think of the kinds of adjustments we make to our own persons as we sit in an empty office just prior to an important interview: Sit up straighter. No, that's too straight, I will seem tense. Try to relaxdon't slouch-I'll blink my eyes to wake up. What should I be doing when they come in? What kind of 
person do I want to appear to be? Close my legs-no, that looks awkward-maybe I should try standing up? Many of the same instructions are given to children as we teach them the body techniques that are considered socially acceptable for their age, gender, or race. There is an aspect of randomness in tinkering-we might also say futzing or fiddling-which is nevertheless constrained by our own learned skills and habits. We are not quite sure what we are aiming at or which standards apply, so we try out different possibilities within a particular range of behaviour, looking for one that feels right. In doing so, we receive continual somatic and perceptual feedback. Rather than having total control over our embodied presence, we find ourselves negotiating with embodiment: coaxing or guiding ourselves in particular directions, holding intrapersonal conversations, and sometimes producing the desired effects through indirect means. For the professional actor or dancer, embodiment is the central material tool or instrument of craft. But even for untrained performers in everyday life, embodiment is the site of an encounter with material reality that exceeds consciousness and will. The tinkered body reacts, sometimes in unexpected ways, and this feeds back into the tinkering process. ${ }^{9}$ The same phenomena that arise when interacting with external substances characterize skilled and mundane interaction with the materiality of embodiment.

If those are examples of tinkering, then tuning suggests a qualitatively different, but no less materially grained, mode of engagement with embodiment. The obvious example is the literal one: vocal tuning. Voices tune, both to themselves across time (melody) and to each other across space (harmony). Tuning offers more immediate positive and negative feedback than tinkering. The harmonic relationship of tuned voices produces an alignment that is more mathematically precise and more sensually resonant. One feels it viscerally when voices slide in and out of tune. The outof-tune voice is perceptually jarring, as is a dancer who does not keep up with unison steps, or a guest who speaks too loudly at the dinner table. These examples of disattunement suggest that tuning is more narrowly aimed than tinkering: one can be 'out of tune' but not 'out of tinker' because tinkering has no clear state of success. Other uses of the breath, such as breathing slowly and deeply in order to calm oneself down, might also be understood as varieties of tuning. (A good voice teacher tunes a student's breathing patterns; a bad voice teacher tinkers with them, perhaps making the situation worse.) In psychotherapy, attunement refers to the resonant alignment of a therapist's body, voice, and affect in relation to a client or patient. In performance studies, the science of mirror neurons has been widely cited as evidence that interpersonal attunement can take place even when one of the parties is apparently passive (McConachie 2008, 65-120). In popular science reporting, brain scans of meditating monks and virtuosic musicians have led to an increased interest in the quantification of embodied states of intrapsychic attunement (Danzico 2011; see also Schmalzl and Kerr 2016). Elsewhere, Mel Y. Chen refers to the need to reject a history of 'racial tuning' in response to racism $(2012,199)$.

Tuning, as in the search for a radio station amidst bands of static, affords multiple possible successful realizations. There is not just one harmony or state of attunement to be found but a number of possible harmonies, even though most randomly selected simultaneous pitches will be disharmonic. While tinkering evokes the randomness of explorative practice, tuning suggests the search for one of several possible states of resonance. Our third term, tracking, promises in contrast a singular goal to be seized; the hunt for a particular desired outcome. In processes of 
tracking, the desired state is out of reach, out of reach, out of reach, and then suddenly within our grasp. Just as De Landa's metalsmith tracks the flash point of a particular metal, so a martial artist searches for the singular dynamic alignment of muscle and bone to pierce an opponent's defense. The correct execution of a pirouette, a gymnastic flip, or a goal in football cannot be achieved through the more patient methods of tinkering and tuning. No matter how long the period of preparation and training, such feats must be conquered in a single moment, a leap of faith, which means that their potential execution must be tracked with the same care as a hunter tracking an animal. This kind of care is as evident in the healing work of a bone-setter or chiropractor who tracks the delicate geometry of the human musculoskeletal system; and in that of a teacher who tracks the learning process of a struggling student, searching for the elusive question or comment that will unlock a particular insight. In everyday life, we track embodied possibilities when we wait for the right moment to ask a question, search for the right person with whom to collaborate, call forth the courage to undertake a difficult action, or direct intimate gestures of touch and sensation to provoke orgasm in our own body or another. ${ }^{10}$

These examples are poetically illustrative, but they are no more metaphorical than the original applications of these terms by Cetina, Pickering, and De Landa to artisanal processes in science and technology. As these examples suggest, embodied arts-including those that structure the practice of everyday life-are in no sense merely social or cultural forms imposed upon an invariable material substrate. Rather, they are concrete ways of grappling with, getting a grip upon, and coming to know the materiality of human embodiment through processes of direct and detailed material negotiation. Engaging such materialities-which every embodied creature must do, not only humans-involves the same kind of fine-grained tinkering, tuning, and tracking that animate artisanal practices and scientific research, even if the objects being handled are at once more intimate and less quantifiable. Embodied arts should therefore equally be understood as privileged sites for practical encounters with the real and for the concrete enactment of ontological inquiries. ${ }^{11}$ It is not enough to see dance, song, and sport as things we do 'with' our bodies, or worse as illustrations of philosophical claims. The varied disciplines of embodied technique must be recognized for their epistemic engagement with reality, which is neither more nor less than a sophisticated and precise negotiation of the basic problem of realism. Moreover, these fields of epistemic engagement are not limited to expert practitioners but occupy each of us throughout our lives, as we continually adapt our embodied habits and skills through processes of tinkering, tuning, and tracking.

As infants, we tinker, tune, and track basic principles of motion and balance. This developmental process is sometimes mistakenly described as that of learning to 'use' our bodies, as if a separate mind made use of a separate body as tool. More accurately, we encounter material reality first of all through embodiment as we discover movement itself. ${ }^{12}$ I recently watched my one-year-old child learn to crawl and then to stand. As of this writing, they are on the cusp of taking their first step. There can be no denying that this process of discovery-although it involves no words or rational conceptualization-is based on the same type of intimate searching that define the artisanal and scientific practices of adults. Of course, the embodied research of infants is not research in the stronger sense of extending a field of knowledge. My child's developmental 
pathway repeats a discovery that has been made countless times before. Nevertheless, for each new human, coordinated movement is a discovery that must be made in practice. Here is the tinkering with fingers and toes, learning what shapes they can make, what movements they can and cannot perform. Here is the tuning of muscles and skeletal alignment, gradually allowing the child to increase their range of motion and control. Here is the tracking of concrete embodied possibilities: to sit, to stand, to walk. My one-year-old is also playing with objects: blocks, fruits, clothing, etc. But their first and most immediate encounter with the practical truth of ontological realism comes in and as embodiment itself.

The 'western' philosophical tradition has largely passed over embodied practice as a necessary but trivial aspect of human being that has nothing much to say to serious questions of ontology. While phenomenology is rightly recognized as having brought everyday embodiment into the heart of philosophy, it does not apply to embodiment the kind of fine-grained attention that recent theorists of practice have given to science and craftwork. Certainly we have yet to see-in continental or analytical philosophy - the specialized embodied practices of martial, healing, and performing arts treated as substantive ontologies alongside those produced by discursive thought or material science. But if the tinkering, tuning, and tracking of fine-grained material practice is a privileged perspective from which to envision new realist ontologies-as the work of Cetina, Pickering, De Landa, Ingold, Sennett, Gibson, and many others suggests-then we can no longer afford to dismiss embodiment as a primary site of such engagement. From the theatrical choreographer to the nervous interviewee to the infant learning to walk, our neverending negotiation with embodiment through various modes of engagement constitutes our primary experimental engagement with reality. Through such engagement we not only learn how to do things but also continually rediscover the emergent contours of what exists. It is no paradox that we encounter ontological realism first of all through our own embodiment, for embodiment is in this sense nothing more than the primary affordance: the first site of that negotiation which makes possible all other negotiations and affordances.

\section{The Fragile Junction}

We now have a working definition of embodiment that does not limit it to the biomedical body, the anatomical body, the socially constructed body, the skilled or expert body, or any other particular mapping, but instead leaves it radically open as an epistemic object: Embodiment is first affordance. Embodiment in this sense is a zone of engagement in which the sediment of relatively reliable pathways (technique) interacts with the emergence of fractally complex material potential. This definition engages with recent critical moves to emphasize the agentic capacity of matter, but it retains a distinctly normative perspective. Embodiment is not just another example of material affordance; it is first or primary affordance, ontologically and epistemologically prior to other affordances. Why take this normative stance? Embodiment is primary affordance in a trivial developmental sense: we must learn to negotiate embodiment before we can 'come to grips' with objects and substances outside our own bodies. But do not the first months of every human's 
embodiment take place within the matrix of gestation, where it is entangled with and reliant upon another body? And is not even the simplest infant negotiation of embodiment, such as learning to eat or suck or crawl, predicated upon a material environment that includes other bodies and substances? Why mark embodiment as first affordance, when it is clearly inseparable from the living ecology of earth and air, food and water? Why draw a conceptual line around embodiment, when it is evidently a gradient, a gradual zone of transition between that which is part of us and that which moves around and through us? Does not this claim to priority reinstate the 'ontotheological binaries of life/matter, human/animal, will/determination, and organic/inorganic' (Bennett 2010, x) against which recent materialist theory has railed?

Paul Rekret has warned that recent theories of realism and materialism may collude with a wider ongoing destabilization of the material grounds for ethical and political mobilization, even when those theories claim to derive from ethical or political sentiments. ${ }^{13}$ As Rekret suggests, there is a risk that dissolving the human as a category can lead us not towards a deepening and expansion of ethical sensibility but rather into the flat ontologies of techno-capitalist fantasy, in which the 'human' disappears precisely insofar as it attains the magical, frictionless status of the commodity (Tsing 2005, 51). Such fantasies are based upon forgetting or suppressing the supply chain: the means of production that bind apparently clean technologies to their dirty origins and the massive division of labour that separates 'start-ups in San Francisco, microchip manufacturing plants in global export processing zones, coltan mines in the Congo', and 'the externalities of these processes through the bioaccumulation of industrial chemicals in food chains, atmospheres, and waterways' (Rekret 2016, 234-5). It is therefore crucial to distinguish between post-humanism, which critiques the anthropocentricism, eurocentrism, and heteropatriarchy of humanism; and posthuman-ism, which offers techno-capitalist fantasies wherein human beings are increasingly severed from our ecological tethers and freed to design ourselves without material limits. ${ }^{14}$ The posthuman (or transhuman, cf. More and Vita-More 2013, 54-55) in this sense takes little interest in embodiment and embodied practice, seeing these as mere steps along a teleological pathway leading to a superhuman technological future. In contrast, the emergent complexity of embodiment can be a crucial resource for posthumanist critique, highlighting the difference between humanity and embodiment as possible grounds for action at every scale.

As a species, we are no more independent of natural ecology than we ever were. It is just that, for some of us, direct engagement with those ecologies has been hidden behind layers and layers of technology. There is then an increasingly urgent need to articulate a meaningful and life-sustaining distinction between technology and ecology, and it is in this context that the ontological and epistemological priority of embodiment as a concept proves important. Urban populations today live inside the massively constructed machine of the city. Into this machine are pumped attenuated lines of biological substance: water, food, medicine, pets. Out of the city are pumped corresponding lines of waste. When city-dwellers go to see 'nature', it looks like an extension of something we have previously encountered in much narrower, more concentrated forms in the city. We recognize this connection and realize that our bodies and its organic fuels are not produced in the same way as buildings, cars, or computers, but derive from an altogether different order of ecology. At the same time, our bodies are intimately linked to the city and its technologies 
because the urban infrastructure is designed to accommodate and support our bodies. (Some bodies more than others.) Our bodies, in other words, are an intermediate zone-a hinge, pivot, or junction-between the ecological and the technological. Theories that do not support a distinction between ecology and technology have no particular interest in embodiment, which becomes merely one among myriad affordances. It is only in recognition of the urgent disbalance between ecology and technology that we have cause to prioritize embodiment as the fragile junction between these domains. In light of this disbalance, embodiment is not just any affordance but first affordance, the affordance from which it might be possible to reorganize the relationship between technology and ecology. It is even worth asking whether embodiment as a concept has developed precisely in response to and in order to cope with this disbalance.

Perhaps, with great optimism of the will, we can imagine a future in which ecology and technology are once again balanced in the sense that no tool or machine is created without an understanding of how it both emerges from and returns to prior ecologies. In this world without waste, where technology operates 'cradle to cradle' (Braungart and McDonough 2002), there would be no need to distinguish between ecology and technology, no grounds for such a distinction, and therefore no concept of embodiment. Technology would then be merely a kind of 'fold' (Deleuze 1993) in ecology, a particulate that emerges from and returns to its ecological foundations. Human embodiment in this world would be part of that fold, requiring no particular ontological primacy to survive. It is only when technology stands in a profoundly destructive and exploitative relationship to ecology that a concept is required through which to distinguish the two and from which to mobilize on behalf of a more balanced technique of living. A vantage point is required from which to understand what 'balance' means, for it is never the 'planet' as a massive object that is in danger but only specific ecologies upon which we as living organisms are dependant. If we are to feel more connected to a forest than to a city, more similar to a coral than to a car-if, in other words, we are to become ecologically sane-then we need to recognize these connections as owing to our embodiment. Not 'the body' as a known thing, but embodiment as an affordance that is both ecological (because it predates technology and can live without it) and technological (because we reconstruct our embodiment when we construct our machines). ${ }^{15}$ Embodiment is ecology technologized, but not in a way that renders the distinction irrelevant. Rather, the intersection or junction of technology and ecology in embodiment is the only perspective from which we might be able to develop a more sustainable ecotechnological practice.

Much work remains to be done if we are to theorize and practice embodiment in ways that promote a liveable relationship between ecology and technology. As theorists of embodiment, we might start by working our way through the philosophy of technology (e.g., Scharff and Dusek 2014) and applying its insights, point by point, to the technique of embodied arts. This would give us some starting points for a philosophy in which embodiment is not sharply distinguished from ecology or technology but rather prioritized as the standpoint from which that crucial distinction can be drawn. It would also give us an entirely new philosophy and politics of performance. 
1 These activities include a book (Spatz 2015); a new Embodied Research Working Group within the International Federation for Theatre Research, which will hold its first meeting at the 2017 conference in São Paulo; and the peer-reviewed, video-based, open access Journal of Embodied Research, launching in early 2017 from Open Library of Humanities <jer.openlibhums.org>.

2 My thinking here begins from a focus on human embodiment, but its implications are not limited by any substantive definition of the human. By suggesting that embodiment is prior to the question of the human, I displace the question of what counts as human — with all its hierarchical and historically racist connotations that onto embodiment as the grounds of all action and experience. This point is clarified in the final section, where I define embodiment as historically contingent and ontologically distinct from the category of the human.

3 Elsewhere (Spatz forthcoming) I call this mode 'phenomenotechnical', following Hans-Jörg Rheinberger's interpretation of Bachelard's extension of phenomenology to include technology and, by implication, technique.

${ }^{4}$ A third domain of encounter that I won't address here is the composition and performance of music. My friend Scott McLaughlin has pointed me toward current musicological discussions about the role of 'critical technical practice' (Agre 1997; Woolford et al. 2010; Orpheus Institute 2016). Contemporary music borrows easily from computer science research because it is premised upon specific advanced technologies, from the harpsichord to the computer. My claim in this essay is that embodied arts are also 'critical technical practices'-indeed they are the first critical technical practices. This is evident as soon as we recognize the extent to which embodied practice is structured no less by technique than those practices which engage with and rely upon technology.

${ }^{5}$ According to Larry Hickman, this criticism is analogous to the one John Dewey leveled at the ancient Greeks: They could not fully grasp the potential of science because they elevated theoretical knowledge over practical knowledge (theoria over praxis and praxis over poeisis). Hickman writes: 'It was Dewey's insight that in the actual productive activities of modern science, as opposed to much of its account of itself and the accounts philosophers have given of it, the Aristotelian hierarchy of the sciences was inverted' (1993: 99, italics original). If Hickman is right, then what we are now witnessing in contemporary science and technology studies is the gradual catchingup of the philosophy of science to its practice.

${ }^{6}$ For further clues towards a phenomenology_or even a critical ontology_of race, see Alcoff (1999); Fassin (2011); Shotwell (2011); Saldanha and Adams (2013).

7 Recent work on disability, animality, and animacy (e.g., Erevelles 2011; Chen 2012) does point towards the material diversity of bodies. These texts might usefully be read alongside the practice theories discussed here.

8 I thank Stephen Purcell for suggesting that I consider the distinct connotations of these three terms.

${ }^{9}$ Unexpected feedback in response to bodily tinkering might today be analyzed under the rubric of affect (Gregg and Seigworth 2010). I suspect there is much to be learned by analyzing affect in relation to technique.

10 The whole realm of embodied engagement with materiality can be mapped onto sexuality. Awkward play feels like tinkering. Greater intimacy is found when sexual contact is a kind of tuning. Prioritizing orgasm, for better or for worse, marks a shift from tuning to tracking. Sexuality should not be underestimated as a site of practical ontology.

11 The 'art' invoked in the phrase 'embodied arts'-as well as in terms like martial arts, performing arts, healing arts, ritual arts, sexual arts-refers not to the unique and ephemeral art-event of romanticism, but rather to art in the sense of craft or technique (Ingold 2001). It is techne extended to include the ways we work with and through embodiment and in recognition that this domain is as large and as important as that which now goes by the cognate label 'technology'.

12 Developmental and evolutionary perspectives on the phenomenology of movement are provided by SheetsJohnstone (2009).

13 Rekret's criticism is aimed at the 'speculative realism' school of philosophy proposed by Graham Harman, Levi Bryant, and others, as well as at the apparently more politically aware theories of Jane Bennett, Rosi Braidotti, and 
Karen Barad. Each of these thinkers deserves further consideration and in the present context I can only outline a general concern with posthuman materialisms. I do think it is important to consider these new and speculative realisms alongside those of Schatzki, Cetina, Pickering, De Landa, Ingold, and others who articulate material agency through detailed studies of artisanal practice. (The work of Deleuze is an important precursor to some but not all of these thinkers.) To follow one example: Like these theorists of craftwork, Bennett's 'political ecology of things' refers to the practices of woodworkers and metallurgists as alternatives to the hylomorphic model of form (2010: 56). She writes: The desire of the craftsperson to see what a metal can do, rather than the desire of the scientist to know what a metal is, enabled the former to discern a life in metal and thus, eventually, to collaborate more productively with it' (60, italics original). Nevertheless, as Bennett partly acknowledges (104), some distinction is still needed between what a metal can do and what a body can do, if only because bodies and metals do not necessarily subscribe to the same set of values regarding what counts as 'productive' in their collaboration.

${ }^{14}$ My thanks to Christopher Morris at Maynooth University for helping me to draw this distinction.

15 It will be pointed out that tool use dates to the beginning of the species. But it is not necessary to draw a strict line around technology in order to claim the priority of embodiment. Early human tool use does not require a concept of embodiment because it does not need to be distinguished from ecology. Only when technology grows to a scale at which it threatens the ecologies that sustain us is there a need to distinguish between the two. This distinction must then be made on the basis of a pivot or junction zone between ecology and technology, which I am calling embodiment.

\section{Works Cited}

Ahmed, Sara. 2006. Queer Phenomenology: Orientations, Objects, Others. Durham, NC: Duke University Press. https://doi.org/10.1215/9780822388074

Agre, Philip. 1997. 'Toward a Critical Technical Practice: Lessons Learned in Trying to Reform Al'. In Social Science, Technical Systems, and Cooperative Work: Beyond the Great Divide, edited by Geof Bowker, Les Gasser, Leigh Star, and Bill Turner, 131-158. Hillsdale, NJ: Erlbaum.

Alcoff, Linda Martin. 1999. 'Towards a Phenomenology of Racial Embodiment'. Radical Philosophy 95: 15-26.

Bengson, John and Marc A. Moffett, eds. 2011. Knowing How: Essays on Knowledge, Mind, and Action. New York: Oxford University Press.

Bennett, Jane. 2010. Vibrant Matter: A Political Ecology of Things. Durham: Duke University Press.

Braungart, Michael and William McDonough. 2002. Cradle to Cradle: Remaking the Way We Make Things. New York: North Point Press.

Chen, Mel Y. 2012. Animacies: Biopolitics, Racial Mattering, and Queer Affect. Durham: Duke University Press. https://doi.org/10.1215/9780822395447

Cetina, Karin Knorr [Karin D. Knorr]. 1979. 'Tinkering Toward Success: Prelude to a Theory of Scientific Practice'. Theory and Society 8 (3): 347-76.

1999. Epistemic Cultures: How the Sciences Make Knowledge. Cambridge: Harvard University Press.

Csordas, Thomas J. 1990. 'Embodiment as a Paradigm for Anthropology'. Ethos 18 (1): 5-47. https://doi.org/10.1525/eth.1990.18.1.02a00010

Danzico, Matt. 2011. 'Brains of Buddhist monks scanned in meditation study'. BBC News. www.bbc.com/news/world-us-canada-12661646

De Landa, Manuel. 1991. War in the Age of Intelligent Machines. New York: Zone Books. 
Deleuze, Gilles. 1993. The Fold: Leibniz and the Baroque. Minneapolis: University of Minnesota Press.

Erevelles, Nirmala. 2011. Disability and Difference in Global Contexts: Enabling a Transformative Body Politic. Basingstoke: Palgrave Macmillan. https://doi.org/10.1057/9781137001184

Fassin, Didier. 2011. 'Racialization: How to Do Races with Bodies'. In A Companion to the Anthropology of the Body and Embodiment, edited by Frances E. Mascia-Lees, 419-434. Sussex: Wiley-Blackwell. https://doi.org/10.1002/9781444340488.ch24

Gibson, James J. 1979. The Ecological Approach to Visual Perception. Hillsdale, NJ: Lawrence Erlbaum Associates.

Gregg, Melissa and Gregory Seigworth, eds. 2010. The Affect Theory Reader. Durham: Duke University Press.

Hickman, Larry A. 1992. John Dewey's Pragmatic Technology. Bloomington and Indianapolis: Indiana University Press.

Ingold, Tim. 2001. 'Beyond Art and Technology: The Anthropology of Skill'. In Anthropological Perspectives on Technology, edited by Michael Brian Schiffer, 17-31. Arizona: Amerind Foundation.

___. 2011. Being Alive: Essays on Movement, Knowledge and Description. New York: Routledge.

Lakoff, George and Mark Johnson. 1999. Philosophy in the Flesh: The Embodied Mind \& its Challenge to Western Thought. New York: Basic Books.

More, Max and Natasha Vita-More. 2013. The Transhumanist Reader. Sussex: Wiley-Blackwell. https://doi.org/10.1002/9781118555927

McConachie, Bruce. 2008. Engaging Audiences: A Cognitive Approach to Spectating in the Theatre. Basingstoke: Palgrave Macmillan. https://doi.org/10.1057/9780230617025

Orpheus Institute. 2016. 'Sound Work: Composition as Critical Technical Practice'. www.orpheusinstituut.be/en/events/sound-work-composition-as-critical-technical-practice

Pickering, Andrew. 1995. The Mangle of Practice: Time, Agency, and Science. Chicago: University of Chicago Press. https://doi.org/10.7208/chicago/9780226668253.001.0001

Rekret, Paul. 2016. 'A critique of new materialism: ethics and ontology'. Subjectivity 9 (3): $225-45$. https://doi.org/10.1057/s41286-016-0001-y

Saldanha, Arun and Jason Michael Adams. 2013. Deleuze and Race. Edinburgh: Edinburgh University Press.

Scharff, Robert C. and Val Dusek. 2014. Philosophy of Technology: The Technological Condition: An Anthology. Sussex: Wiley-Blackwell.

Schmalzl, Laura and Catherine E. Kerr. 2016. Neural Mechanisms Underlying Movement-Based Embodied Contemplative Practices. Frontiers Research Topic Ebook. www.frontiersin.org/books/Neural Mechanisms Underlying MovementBased Embodied Contemplative Practices/916

Sennett, Richard. 2009. The Craftsman. New York: Penguin Books.

Sheets-Johnstone, Maxine. 2009. The Corporeal Turn: An Interdisciplinary Reader. Imprint Academic.

_-_. 2015. 'Embodiment on Trial: A Phenomenological Investigation'. Continental Philosophy Review 48: 23-39. https://doi.org/10.1007/s11007-014-9315-z

Shotwell, Alexis. 2011. Knowing Otherwise: Race, Gender, and Implicit Understanding. University Park: Pennsylvania State University Press.

Sparrow, Tom. 2014. The End of Phenomenology: Metaphysics and the New Realism. Edinburgh: Edinburgh University Press.

Spatz, Ben. 2015. What a Body Can Do: Technique as Knowledge, Practice as Research. London and New York: Routledge.

__- (forthcoming). 'Colours like Knives: Embodied Research and Phenomenotechnique in Rite of the Butcher'. Contemporary Theatre Review. 
Thévenot, Laurent. 2001. "Pragmatic regimes governing the engagement with the world." In The Practice Turn in Contemporary Theory, eds. Theodore R. Schatzki, Karin Knorr Cetina, and Eike von Savigny, 64-82. London and New York: Routledge.

Tsing, Anna. 2005. Friction: An Ethnography of Global Connection. Princeton: Princeton University Press.

Welsh, Talia. 2014. "Philosophy as Self-Transformation: Shusterman's Somaesthetics and Dependent Bodies." Journal of Speculative Philosophy 28 (4): 489-504. https://doi.org/10.5325/jspecphil.28.4.0489

Woolford, Alan F., Sally Jane Norman, and Cecile Chevalier. 2010. 'Crafting a Critical Technical Practice'. Leonardo 43 (2): 202-203. https://doi.org/10.1162/leon.2010.43.2.202

\section{Biography}

Ben Spatz is Senior Lecturer in Drama, Theatre and Performance at University of Huddersfield; UK Arts \& Humanities Research Council Leadership Fellow (2016-2018); author of What a Body Can Do: Technique as Knowledge, Practice as Research (Routledge 2015); convener of the Embodied Research Working Group within the International Federation for Theatre Research; and editor of the Journal of Embodied Research, a peer-reviewed, video-based journal launching in 2017 from Open Library of Humanities. They have been invited to speak at the British Library, the Centre for Performance Research, University of Kent, University of Cardiff, Maynooth University, and University of the Arts Helsinki. Ben's current research extends the interdisciplinary methodology of embodied research into postcolonial jewish studies and will be presented in 2017 at multiple venues in the UK, US, and Poland. www.urbanresearchtheater.com 